\title{
WORK-RELATED MUSCULOSKELETAL DISORDERS AMONG PHYSICAL THERAPISTS: A COMPREHENSIVE NARRATIVE REVIEW
}

\section{MOHAMMAD MILHEM ${ }^{1}$, LEONID KALICHMAN ${ }^{1}$, DAVID EZRA ${ }^{2}$, and DEBORAH ALPEROVITCH-NAJENSON ${ }^{1,3}$}

${ }^{1}$ Ben-Gurion University of the Negev, Beer Sheva, Israel

Faculty of Health Sciences, Department of Physical Therapy, Recanati School for Community Health Professions

${ }^{2}$ The Academic College Tel Aviv-Jaffo, Jaffo, Israel

School of Nursing Science

${ }^{3}$ Tel Aviv University, Tel Aviv, Israel

Sackler Faculty of Medicine, Department of Environmental and Occupational Health

\begin{abstract}
Healthcare workers, especially those with direct patient contact are amongst professions with the highest rate of workrelated musculoskeletal disorders (WMSDs), physical therapists (PTs) being one of them. Our objective was to review current knowledge relating to the prevalence, risk factors and prevention of WMSDs among PTs. Pubmed, Google Scholar and PEDro databases were searched for terms relating to WMSDs in PTs from inception to 2015. The prevalence of WMSDs among PTs was high, with lifetime prevalence reported as 55-91\%, and 12-month prevalence ranges 40-91.3\%, and the lower back as the most frequently affected, with estimates of a lifetime prevalence ranging 26-79.6\%, and a 12-month prevalence ranging $22-73.1 \%$, followed most often by the neck, upper back and shoulders. The major risk factors for workrelated low back pain (LBP) were: lifting, transferring, repetitive movements, awkward and static postures, physical load, treating a large number of patients in a single day and working while injured. Low back pain seems to be age- and genderrelated with a higher prevalence in females, younger PTs and PTs working in rehabilitation settings. Physical therapists, as a consequence of work-related LBP, may seek treatment, modify their daily living and leisure (lifestyle) activities, use aids and equipment or change their specialty area either within the profession or by leaving it. Skills and knowledge as to correct body mechanics do not prevent work-related injuries. Mechanical aids used for a patient transfer should be adopted by PTs and new strategies should be developed to reduce their WMSDs without compromising the quality of treatment. Int J Occup Med Environ Health 2016;29(5):735-747
\end{abstract}

Key words:

Prevention, Physical therapists, Musculoskeletal disorders, Risk factors, Work related, Work settings

\section{INTRODUCTION}

Occupational factors linked to musculoskeletal disorders were identified as early as in the 18th century [1]. According to the World Health Organization (WHO), the term work-related musculoskeletal disorders (WMSDs) "describes a wide range of inflammatory and degenerative diseases and disorders that result in pain and functional impairment. They arise when individuals are exposed to work activities and conditions that significantly contribute

Received: February 25, 2015. Accepted: November 12, 2015.

Corresponding author: D. Alperovitch-Najenson, Ben-Gurion University of the Negev, Faculty of Health Sciences, Department of Physical Therapy, Recanati School for Community Health Professions, P.O. Box 653, Beer-Sheva 84105, Israel (e-mail: deborah@bgu.ac.il, deborahalp@gmail.com). 
to their development or exacerbation, but which may not be their sole cause" [2].

The WHO declared that work environment significantly contributes to work-related diseases, partially caused by adverse or aggravated working conditions, accelerated or exacerbated by workplace exposures [2,3]. Work-related musculoskeletal disorders cause substantial economic losses to individuals as well as to the community [4]. Healthcare workers, especially those with a direct patient contact, are amongst professions with the highest rate of WMSDs due to their job demands and positions maintained throughout the day [5].

Work-related musculoskeletal disorders are considered one of the largest health problems amongst physical therapists (PTs), low back pain (LBP) being the most common disorder [6-14]. The practice is physically demanding, involving repetitive tasks, high force manual techniques for treating patients, techniques that exert direct pressure on certain joints during the treatment, awkward positioning of joints during certain maneuvers and prolonged constrained postures [7].

The purpose of this paper was to review current knowledge relating to the prevalence, risk factors and prevention methods of WMSDs among PTs, with a special focus on LBP.

\section{MATERIAL AND METHODS}

PubMed, Google Scholar and PEDro databases were searched from inception until April 2015 using a predefined strategy for the following key words: work related musculoskeletal disorders, physical therapists, physiotherapists, low back pain, prevalence, risk factors, and prevention strategies. There were no search limitations. Titles and abstracts of all relevant articles were reviewed. All studies written in English of any design or methodological quality and dealing with WMSDs in PTs were included. Study protocol articles and articles with unavailable full text in the libraries of Tel Aviv and
Ben-Gurion of the Negev universities were excluded. The reference lists of all the retrieved articles were also searched.

The whole material was critically analyzed. We are aware of the fact that such a traditional approach to narrative reviews has much more potential for bias than systematic reviews or meta-analyses. However, we endeavored to be inclusive and open-minded.

\section{RESULTS}

\section{Prevalence of WMSDs and LBP in PTs}

Studies have evaluated lifetime and 12-month prevalence of WMSDs in PTs (Table 1). The prevalence of WMSDs among PTs has been found to be high, with lifetime prevalence reported as 55-91\% [11,12,15-17], and 12-month prevalence ranges $40-91.3 \%$ [15-18].

In all the reviewed studies, lower back was the most frequently affected in PTs (Table 1), with estimates of a lifetime prevalence ranging 26-79.6\% [9-12,16,17,19], and a 12-month prevalence ranging $22-73.1 \%$ [8,16-18,20-22], followed most often by the neck, upper back and shoulders. American Physical Therapy Association identified work-related LBP among PTs as an important issue to be addressed and formed a task force to investigate the problem.

\section{Risk factors for work-related LBP \\ Physical load}

Hard physical work (Table 1), with tasks involving joint loading, extreme flexion of the trunk, frequent heavy lifting and transferring patients, maintaining an awkward or static posture, bending, twisting, working in the same position for long periods of time and psychological stress have been reported as causal factors for back injuries in healthcare workers [8-12,15-23].

Physical therapists may routinely perform activities such as transferring dependent patients, assisting patients during gait, providing manual resistance 
Table 1. Lifetime and 12-month prevalence of work-related musculoskeletal disorders (WRMD), and risk factors

\begin{tabular}{|c|c|c|c|c|}
\hline \multirow[t]{2}{*}{ Study } & \multirow{2}{*}{$\begin{array}{c}\text { Study } \\
\text { group } \\
{[\mathrm{n}]}\end{array}$} & \multicolumn{2}{|c|}{$\begin{array}{c}\text { Prevalence } \\
{[\%]}\end{array}$} & \multirow[t]{2}{*}{ Risk factor } \\
\hline & & lifetime & 12-month & \\
\hline Shehab et al. [12] & 100 & $\operatorname{LBP}(70)$ & & lifting, carrying \\
\hline Rugelj [19] & 133 & $\begin{array}{l}\text { LBP }(73.7) \\
\text { neck }(19.5) \\
\text { shoulders }(15) \\
\text { wrists/hands }(15)\end{array}$ & & lifting and handling patients \\
\hline Cromie et al. [15] & 536 & $91^{*}$ & $\begin{array}{l}82.8^{*} \\
\text { LBP }(62.5) \\
\text { neck }(47.6) \\
\text { upper back }(41) \\
\text { thumbs }(33.6)\end{array}$ & $\begin{array}{l}\text { lifting and transferring heavy patients, } \\
\text { working in the same position for long } \\
\text { periods, treating a large number of } \\
\text { patients a day, working in awkward } \\
\text { positions, bending or twisting the back }\end{array}$ \\
\hline $\begin{array}{l}\text { Alperovitch-Najenson } \\
\text { et al. [22] }\end{array}$ & 26 & & $\begin{array}{l}\text { LBP }(73.1) \\
\text { neck }(57.7) \\
\text { shoulders }(42.3) \\
\text { upper back }(34.6)\end{array}$ & $\begin{array}{l}\text { manual patient transfer, trunk } \\
\text { bending, walking assistance }\end{array}$ \\
\hline Bork et al. [20] & 928 & & $\begin{array}{l}\text { LBP }(45) \\
\text { wrist and hands (29.6) } \\
\text { upper back (28.7) } \\
\text { neck }(24.7)\end{array}$ & $\begin{array}{l}\text { lifting or transferring patients, treating } \\
\text { an excessive number of patients in } \\
\text { a day, awkward and cramped positions }\end{array}$ \\
\hline Holder et al. [8] & 623 & & $\begin{array}{l}\text { LBP }(62) \\
\text { upper back, wrist and } \\
\text { hand (23) } \\
\text { neck (18) (24-month } \\
\text { prevalence) }\end{array}$ & $\begin{array}{l}\text { transferring a patient, lifting, } \\
\text { responding to an unanticipated } \\
\text { or sudden movement by a patient }\end{array}$ \\
\hline Rozenfeld et al. [17] & 112 & $\begin{array}{l}83^{*} \\
\text { LBP (79.6) } \\
\text { neck (59) } \\
\text { upper back (54) } \\
\text { wrist and thumbs (46.2) }\end{array}$ & $\begin{array}{l}80^{*} \\
\text { LBP }(59.8) \\
\text { neck }(45.5) \\
\text { upper back }(41.1) \\
\text { shoulders }(42.2)\end{array}$ & $\begin{array}{l}\text { treating a large number of patients } \\
\text { in one day, performing same task } \\
\text { over and over, lifting or transferring } \\
\text { dependent patients }\end{array}$ \\
\hline Alrowayeh et al. [18] & 212 & & $\begin{array}{l}47.6^{*} \\
\text { LBP }(32) \\
\text { neck }(20.2) \\
\text { upper back }(19) \\
\text { shoulder }(12.6)\end{array}$ & lifting, transferring, manual therapy \\
\hline West and Gardner [16] & 217 & $\begin{array}{l}55^{*} \\
\text { LBP (35) } \\
\text { hand (25) } \\
\text { neck (24) } \\
\text { mid back (19) }\end{array}$ & $\begin{array}{l}40^{*} \\
\text { LBP (22) } \\
\text { neck (20) } \\
\text { hand (14) } \\
\text { mid back (11) }\end{array}$ & $\begin{array}{l}\text { lifting or transferring, working in } \\
\text { the same position for long periods, } \\
\text { static postures, continuing to work } \\
\text { while injured or hurt, bending and } \\
\text { twisting movements }\end{array}$ \\
\hline Salik and Ozcan [11] & 120 & $\begin{array}{l}85^{*} \\
\text { LBP (26) } \\
\text { wrist/hand (18) } \\
\text { shoulder (14) } \\
\text { neck (12) }\end{array}$ & & $\begin{array}{l}\text { transferring the patient, performing } \\
\text { repetitive tasks, lifting }\end{array}$ \\
\hline
\end{tabular}


Table 1. Lifetime and 12-month prevalence of work-related musculoskeletal disorder (WRMD), and risk factors - cont.

\begin{tabular}{|c|c|c|c|c|}
\hline \multirow[t]{2}{*}{ Study } & \multirow{2}{*}{$\begin{array}{c}\text { Study } \\
\text { group } \\
{[\mathrm{n}]}\end{array}$} & \multicolumn{2}{|c|}{$\begin{array}{c}\text { Prevalence } \\
{[\%]}\end{array}$} & \multirow[t]{2}{*}{ Risk factor } \\
\hline & & lifetime & 12-month & \\
\hline Molumphy et al. [10] & 337 & LBP (29) & & $\begin{array}{l}\text { lifting with sudden maximal effort, } \\
\text { bending and twisting }\end{array}$ \\
\hline Adegoke et al. [21] & 126 & & $\begin{array}{l}91.3^{*} \\
\text { LBP (69.8) } \\
\text { neck (31.1) } \\
\text { shoulders (22.2) } \\
\text { wrists/hands (20.6) }\end{array}$ & $\begin{array}{l}\text { treating large number of patients in } \\
\text { a day, working in the same position } \\
\text { for long periods }\end{array}$ \\
\hline $\begin{array}{l}\text { Mierzejewski } \\
\text { and Kumar [9] }\end{array}$ & 311 & $\operatorname{LBP}(49.2)$ & & $\begin{array}{l}\text { patient handling, bending, bending } \\
\text { and twisting, stooping, lifting, lifting } \\
\text { and twisting, carrying, pulling/pushing }\end{array}$ \\
\hline
\end{tabular}

LBP - low back pain.

* Lifetime/12-month prevalence of WRMD.

and lifting heavy and cumbersome equipment. Such work tasks put PTs at risk of both acute and cumulative LBP. The primary risk factors for low back injuries in PTs include: transferring (30\%), lifting (25\%) and responding to a patient's anticipated or sudden movement $(24 \%)$ [8]. The most common job-related tasks, reported by Molumphy et al. [10], contributing to LBP have been "lifting with a sudden maximal effort" and "bending and twisting." In Shehab et al. [12] study from Kuwait $54.3 \%$ of PTs reported that "lifting and carrying" was the major activity precipitating work-related LBP. Similarly, West and Gardner [16] have reported that among 217 PTs from Queensland, Australia 35\% stated "lifting and transferring dependent patients" was the most common risk factor for LBP.

The most important risk factors commonly identified by PTs were: "treating a large number of patients in one day" $(83.5 \%)$, "working in the same position for long periods of time" (71.3\%) and "lifting or transferring dependent patients" (67.8\%). Previous studies have similarly identified "treating a large number of patients in one day," "working in the same position for long periods of time" $[15,16,20]$ and "lifting or transferring dependent patients" $[8,15,16,24]$ as the factors most associated with work-related LBP in PTs. Additionally, "bending and twisting" was associated with an increased risk of LBP. "Performing the same task over and over" was the risk factor that injured implicated PTs most often [7]. In contrast, "working with confused or agitated patients," "reaching or working away from the body" and "inadequate training in injury prevention" were not cited as important factors [7,21].

Landry et al. [25] have found that $>75 \%$ of healthcare workers stated that LBP was related to work duties. Low back pain was associated with a direct patient contact and performing patient lifts/transfers. Health professionals who performed patient lifts/transfers were more likely to report LBP than those who did not perform such activities. These findings confirm that the incremental risk may be associated with the frequency of lifts/transfers.

\section{Age: differences between younger and older PTs}

Mierzejewski and Kumar [9] have found that the initial onset of work-related LBP frequently occurred within the first 5 years of practice and before the age of 30. Cromie et al. [15] in an Australian study have reported that more 
than $50 \%$ of PTs had the first episode of work-related LBP during their first 5 years of practice. Holder et al. [8] have also reported that the incidence of WMSDs is the highest within the first 5 years of practice and most common in junior PTs and newly qualified graduates.

In the chartered society of physiotherapy (CSP) members [7], a greater number of participants $(\mathrm{N}=926,59 \%)$ were $\leq 30$ years old when their most serious WMSD occurred. On average, participants were 31.2 years old when they have first experienced their most serious injury [7]. Molumphy et al. [10] have found that in $64 \%$ of PTs the first episode of LBP occurred at the age $\leq 30$ years; $58 \%$ experienced their first episode within four years of qualifying, indicating a particular vulnerability amongst younger, newly qualified PTs.

Bork et al. [20] have shown that for those $>55$ years old, the 1-year prevalence for work-related LBP, was approximately 35\%; the prevalence of work-related LBP ranged $42-52 \%$ for ages $25-50$ years. On the other hand, Cromie et al. [15] have shown that the prevalence of pain or discomfort in the lower back for ages 50-59 years and $\geq 60$ years was $60 \%$ and $50 \%$, respectively; however, the highest prevalence $(80 \%)$ has been found in the youngest age group (20-29 years).

In Kuwait, Alrowayeh et al. [18] have found that the prevalence of work-related LBP during the preceding 12-months was associated significantly with the participants' age, occurring more often in younger age groups (20-40 years). The 12-month prevalence of LBP in age groups 20-30 years, 31-40 years, 41-50 years and $\geq 50$ years were: $12.2 \%, 14.6 \%, 3.7 \%$, and $1.4 \%$, respectively.

King et al. [13] have evaluated the differences between WMSDs amongst older and younger occupational therapists and PTs. Amongst older workers, 60\% complained of LBP; $43 \%$ of whom reported work-related pain or discomfort, quite similarly $63 \%$ of their younger colleagues complained of LBP, of whom $47 \%$ reported work-related pain. When compared with their younger counterparts, older workers were more unlikely to seek treatment because of their symptoms, miss work, work while in pain or limit patient contact time, but they were more likely to report a job change as a result of their symptoms.

Only Rugelj [19] from Slovenia has reported that LBP was more common in older PTs. Lifetime prevalence, "ever had severe back pain," was as high as $73.7 \%$; 50.4\% reported LBP several times. Of the $27.1 \%$ respondents who did not report LBP, the majority (66.6\%) were $20-40$ years old. In the respondents who experienced LBP numerous times, $74.6 \%$ were $31-50$ years old. Of all the respondents, $18 \%$ had visited a physician once and $11.3 \%$ several times; the majority were $31-50$ years old, $21 \%$ had been on sick leave due to LBP: $15 \%$ once and $6 \%$ several times. Approximately half (47\%) of the PTs were convinced that their LBP was work-related, 21.1\% thought that their LBP was not related to their practice and $15.8 \%$ couldn't decide. Most PTs alleviated their LBP by rest (40.6\%), physiotherapeutic treatment $(50.4 \%)$, exercise or pain killing drugs.

Older workers appeared more likely to receive surgical interventions for their injuries [26] and therefore, may have experienced subsequent disability due to age-related changes in cognitive function, health and recuperative ability [27].

\section{Sex: differences between male and female PTs}

Bork et al. [15,20] have reported that the incidence of WMSDs is associated with gender of the therapists, with females complaining more often. This finding is in agreement with several other studies $[9,12,13,20,21]$ documenting that WMSDs prevalence among female PTs ranges $73-100 \%$.

In Kuwait, the 12-month prevalence of LBP in female PTs was $22.6 \%$ compared to $9.4 \%$ in males [18]. The prevalence of shoulder and neck WMSDs was $17 \%$ and $12 \%$ in females, respectively, and $2.3 \%$ and $0.9 \%$ in 
males. No significant association was found between PT gender and the prevalence of elbow, upper back, hip/ thigh, knee, and ankle/foot WMSDs [18].

In another study in Kuwait [12], a point prevalence rate of work-related LBP was 57\% (31.6\% in males and $68.4 \%$ in females). The lifetime prevalence was $70 \%$ (61.8\% in males, $74.2 \%$ in females). In general, more females than males reported LBP, but it was not significant. The difference in the median pain score between male and female PTs was also insignificant. Physical disability before experiencing LBP was mainly musculoskeletal in both females and males, but higher among those with work-related LBP (23\%) than non-workrelated LBP (10\%). Moreover, females (21\%) reported higher musculoskeletal disability than males (15\%). Of $13 \%$ with work-related LBP before entering the profession, $76.5 \%$ were females with $14 \%$ of them reporting mild functional limitations in their daily activities before entering the profession [12]. No difference was found in the prevalence of work-related LBP amongst Turkish female PTs (85.9\% females and $82.1 \%$ males) [11].

Glover et al. [7] have also reported a higher prevalence of LBP among females than among their male colleagues amongst 2688 Chartered Society of Physiotherapy (CSP) members. Females reported the prevalence of low back (45\%), neck (14\%), shoulder (7\%) and wrist/hand $(7 \%)$ injury more often than their male colleagues. Males suffered more upper back (18\% vs. $12 \%)$, knee (6\% vs. $3 \%)$, elbow/forearm (3\% vs. $1 \%)$ and hip/ thigh (3\% vs. 1\%) problems than females. Both females and males similarly suffered from thumb injuries (both $10 \%$ ).

In the USA, female PTs had a higher prevalence of selfreported symptoms in every anatomical area except for the knees. The lower back was the most injured area. The prevalence of WMSD in the neck, upper back, low back, wrists and hands was greater in female PTs. Furthermore, $73 \%$ of female PTs reported at least one musculoskeletal symptom compared with $57 \%$ of male PTs [20].

In Israel [17], female PTs exhibited an increased risk of WMSDs in the neck/upper back and shoulders/elbows, demonstrating that the female gender is associated with $21 \%$ increased likelihood of injury to the neck/ upper back, and $13 \%$ increased likelihood of injury to the shoulders/elbow areas. However, Cromie et al. [15] have reported that male PTs had increased odds of reporting neck symptoms, wrist symptoms, and thumb symptoms compared with their female colleagues.

\section{Differences in work settings}

Seventy-five percent of PTs working in rehabilitation settings experienced LBP compared to $64 \%$ of those working in outpatient settings and $63 \%$ of those working in hospitals [8]. Scholey and Hair [24] have found the rehabilitation setting to be a stressful work environment, thereby, increasing the risk of low back injury. Physical therapists reported that their most significant injury had first occurred whilst working with general musculoskeletal outpatients $(31 \%)$, in neurological rehabilitation $(14 \%)$ and caring for the elderly $(12 \%)$. These three major clinical areas produced serious WMSDs amongst PTs [7].

Practice setting proved to be an important factor for both PTs and physical therapist assistants (PTAs) who sustained wrist or hand injuries [8]. Thirty-eight percent of PTs in skilled nursing facilities and 32\% of PTs in outpatient settings sustained a wrist or hand injury compared to only $13 \%$ of PTs injured in hospitals and $0 \%$ injured while performing home-based care.

Rozenfeld et al. study [17] of PTs who worked in rehabilitation centers and PTs who worked in outpatient clinics, has found that amongst 112 PTs (64 worked in rehabilitation centers, 59 in outpatient clinics), the highest lifetime prevalence rates for WMSDs were in the lower back (79.6\%). Physical therapists practicing in rehabilitation centers reported a higher annual prevalence of lower back injuries 
than their colleagues in outpatient clinics $(79.2 \%$ compared to $35.4 \%$ ).

In contrast, Glover et al. [7] have found that clinical setting was significantly related to PTs' most serious injuries. Physical therapists $(\mathrm{N}=1796)$ reported that their most significant injury had occurred whilst working with general musculoskeletal outpatients $(\mathrm{N}=554,31 \%)$, in neurological rehabilitation $(\mathrm{N}=242,14 \%)$ and caring for the elderly $(\mathrm{N}=215,12 \%)$. The relationship between the type of complaint (e.g., spinal, upper limb/lower limb problems) and clinical setting was evaluated and the effect was found significant.

A higher proportion of upper limb injuries occurred amongst PTs [7] working with general musculoskeletal outpatients. Of all respondents whose major or most significant injury had been to the wrist or hand, 49\% (59/120) experienced their first symptoms while working with general musculoskeletal outpatients which increased to $76 \%$ (139/184) for respondents whose most significant injury had been to their thumb. Of PTs reporting LBP as their most serious musculoskeletal disorder, neurological rehabilitation was the setting of the first onset of the symptoms $(18 \%, 139 / 776)$, followed by general musculoskeletal outpatients (17\%, 129/776), elderly care $(14 \%, 112 / 776)$ and orthopedics $(11 \%, 87 / 776)$.

Alrowayeh et al. [18] have found that the prevalence of work-related LBP was not significantly associated with work settings (except for hand/wrist complaints), although, they have reported that the highest WMSDs was in the lower back and the most work venues with the high prevalence of LBP were general (13.2\%) and rehabilitation hospitals (10.3\%). Furthermore, the highest prevalence of work-related LBP according to the area of specialty was orthopedics (9.9\%) and pediatrics (6.6\%). Similarly, Shehab et al. [12] have reported that the highest prevalence of work-related LBP occurred in general hospitals and rehabilitation centers, which were higher than those reported by Alrowayeh et al. [18], with $44 \%$ and $41 \%$, respectively.
Moreover, he has found that the prevalence of work-related LBP according to the area of specialty was orthopedics (34\%), neurology (24\%), and pediatrics (14\%).

Salik and Ozcan [11] have categorized PTs according to the practice setting and found that LBP was the most common WMSD in all subgroups. The highest prevalence was in PTs who worked in cardiopulmonary rehabilitation $(30 \%)$, orthopedic rehabilitation $(29.5 \%)$ and neurological rehabilitation (28\%); the lowest was in general physical therapy practice settings (25.7\%).

Bork et al. [20] have found that PTs working in hospitals reported a higher prevalence of musculoskeletal problems in every anatomical area except for wrists/hands and hips/ thighs than non-hospital-based PTs did. The prevalence of WMSDs was significantly higher in the low back and ankles for PTs working in hospitals.

\section{Impacts, responses and prevention strategies}

Strategies used by PTs to avoid WMSDs include the use of aids, special equipment and so called "self-protective behaviors." Aids and equipment used to reduce physical demands of the PTs work include: height-adjustable beds, lifting belts, slide boards, splints, and stools on casters ("wheelie stools") [28]. Lately, lifts and sliding sheets have been highly recommended [29].

Cromie et al. [15] have defined "self-protective behaviors" as outsourcing, preventive or reactive strategies. Outsourcing strategies shift all or part of a therapist's workload to another person. These strategies include reducing the load by acquiring help when transferring patients. A PT can use PTAs' assistance in lifting a patient rather than lifting him/her alone [30]. Preventive strategies are meant to alter the technique or the environment and thus, avoid stress to a therapist's body. A therapist's position during work can be related to the development of LBP [31]. Strategies to modify a therapist's position or adjust bed height to prevent injury are in this category. 
Another possible preventive strategy is to introduce breaks and changes in posture in order to reduce the risk of injury, as well as to warm up before performing a procedure [32]. Reactive strategies are those developed by a therapist in response to an injury (or a perceived risk of injury). These strategies include movements that aid in avoiding aggravating factors, such as using a different part of the body to administer a manual technique, which can protect the upper limb from overuse [33], in addition to substituting electrotherapy for certain manual techniques.

Responses to WMSDs may include a search for new treatments, modifying activities of daily living (ADL) and leisure (lifestyle) or making changes in their specialty area either within the profession or by leaving the profession entirely. Different types of responses can be divided into two categories: those aimed at reducing the effects of stress on the body as much as possible and those designed to avoid future exposure. The effects of strain may be reduced by receiving treatment, modifying lifestyle or removal from stressors. Sick leave and workers' compensation are two ways of reducing the effects of strain. Bork et al. [20] have reported that $2.8 \%$ of therapists missed work due to LBP. Molumphy et al. [10], reporting on avoiding future exposure, have found that $18 \%$ of therapists with LBP changed their work setting and $12 \%$ reduced their hours of patient contact time; however, none left the profession as a consequence of work related LBP. Alternatively, therapists tended to move from acute care and rehabilitation settings to less acute care settings. Bork et al. [20] have reported that $25 \%$ of therapists had changed their work activities as a consequence of WMSDs, most frequently by changing techniques, work postures or body mechanics. Over $61 \%$ of the PTs indicated that they had treated themselves or had sought treatment from a colleague for a WMSD.

Holder et al. [8] have described responses to WMSDs among PTs and PTAs; $36 \%$ of PTs and $49 \%$ of PTAs stated that they had reported their injury to an appropriate individual in their workplace; $34 \%$ of PTs and $44 \%$ of PTAs visited a physician and $25 \%$ of PTs, and $23 \%$ of PTAs reported losing a half day or more from work; PTs cited improvements in body mechanics (50\%), increased use of other personnel (43\%), and frequent changing their work position (24\%). Ninety-two percent of the PTs and $93 \%$ of the PTAs reported that they had not limited their patient contact time as a result of their injury, and $85 \%$ of the PTs and $86 \%$ of the PTAs stated that they had not limited their area of practice after sustaining an injury. More PTAs (14\%) than PTs (8\%) stated that they would consider a job change because of their injury or risk of sustaining another injury.

Cromie et al. [15] have reported that PTs used various aids to reduce the strain on their body while working in order to minimize the effects and risks of developing WMSDs. Of 536 PTs, 77.4\% used an adjustable bed or plinth, $45.3 \%$ used a wheelie stool, $16 \%$ used lifting belts, $10.3 \%$ used slide boards, $6.7 \%$ used splints, and $22.9 \%$ used other (unspecified) assistance. Only $9.3 \%$ used no aids to reduce physical strain on their bodies. Approximately $75 \%$ changed or modified treatment at some time as a result of WMSDs.

Only $7.4 \%$ of the 488 (91\%) therapists who had experienced WMSDs [15] lodged a worker compensation claim; $13.6 \%$ took sick leave, and $84.2 \%$ continued working with discomfort. Furthermore, of the 335 PTs who reported LBP during the preceding year $(62.5 \%)$, only $12.5 \%$ were prevented from working due to LBP, but $41.5 \%$ were prevented from performing their normal leisure activities and ADL. After all 17.7\% of PTs changed their specialty area of practice or left the profession altogether as a result of WMSDs and were more likely to have experienced moderately severe LBP during the preceding year than those who had not. Out of those who changed their specialty area of practice, $42 \%$ left neurology and rehabilitation to work in another area. 
Mierzejewski and Kumar [9] have found that 49\% reported LBP due to work activity. Some $(35 \%)$ continued to work despite their back pain, while $13.7 \%$ ceased working as a result of the injury. In Britain, Scholey and Hair [24] have also found that $88 \%$ of the therapists with work-related LBP had taken measures to avoid a recurrence, which included back care (43\%), exercise $(20 \%)$ and change of bed or chain (37\%). Only $43 \%$ had consulted their general practitioner.

Glover et al. [7] in a study of 2688 CSP, have found that $58 \%$ reported a previous 12-month prevalence of WMSDs with $37.2 \%$ reporting work related LBP. Of those reporting work-related spinal injuries, $66 \%$ had sought physiotherapy treatment from another colleague (low back (30.4\%), neck (21.3\%), upper back (15.2\%)).

In Israel, Rozenfeld et al. [17] have found that among 127 PTs working in 5 rehabilitation centers and 6 outpatient clinics, $80 \%$ reported WMSDs during the preceding year and $59.8 \%$ reported LBP. Of those with workrelated LBP, 22.4\% of injured PTs were absent from work and $32.3 \%$ avoided performing ADL or leisure activities. Almost all PTs (95.3\%) who had worked in rehabilitation centers reported receiving help from others in handling heavy patients; $95.8 \%$ of PTs in outpatient clinics reported using different parts of their body to administer manual techniques and $50 \%$ warmed up and stretched before performing manual techniques. Additionally, $64.5 \%$ of PTs changed their treatment approach, $11 \%$ changed their work setting and over $20 \%$ of PTs with lower back injuries took time off from work.

Cromie et al. [34] have proposed guidelines for practice to reduce WMSDs among PTs. Australian occupational health and safety legislation ensures that an employer and employee meet minimum standards for injury prevention. The legislation is based on a risk management model in which a hierarchy of control prescribes hazard identification, risk assessment, risk control and review. Legislation and codes of practice require employers to undertake risk assessment and implement risk control measures, thus, ensuring that training and education are implemented only after the work environment and work systems have been modified, the objects changed and mechanical aids introduced [35].

\section{DISCUSSION}

Physical therapists are at high risk of WMSDs with the low back as the major body part affected [6-8,10,15,16,36]. The prevalence rates widely vary between the studies, perhaps due to the use of different case definitions.

Most of the studies have found that in addition to physical and personal factors, psychosocial job demands, social relations at work and interpersonal cultural factors were associated with WMSDs.

Lifting or transferring dependent patients was reported as the factor most likely to contribute to work-related LBP $[10,12,15,16,24]$. Other postural factors relating to working posture or position of PTs and workload factors relating to the frequency or repetitiveness of treatment and time management issues were also contributing factors to work-related LBP $[7,15,16,20,21]$.

Physical therapists are mostly at risk of work-related injuries and consequent LBP within the first 5 years of employment and before the age of $30[8,10,15]$. Physical therapists beginning work are often young, usually $<30$ years of age, suggesting that newly employed therapists are at risk of injury early in life. The high prevalence of LBP in younger PTs was thought to be a result of newly qualified therapists tending to work in physically demanding clinical areas such as rehabilitation and intensive care units [10] with less knowledge and minimal skills early in their careers $[10,20]$. Bork et al. [20] have suggested that the age-prevalence trend, lower in older PTs, resulted from PTs moving out of patient care as they gained experience and into administrative positions that are less physically demanding. An alternative explanation of the low prevalence of workrelated LBP in older PTs may be related to a survivor 
bias. As PTs become older, the survivors are those who develop strategies for coping with physical demands of the job and continue to treat patients. Although the literature points to an increased risk of injury due to associated age-related changes, there is also a general consensus that as age increases, the number of injuries and injury rates decline [37].

Most studies have indicated that female PTs had a more increased risk of developing work-related LBP than male PTs $[7,9,13,15,17,20]$. The higher prevalence of workrelated LBP among female PTs may be related to the fact that females are generally smaller and physically weaker than males, which may place them at a disadvantage during care tasks, particularly when lifting and transferring patients.

Low back pain is the most frequent explanation for work absence in comparison to injuries in other body areas [8,9,12,15,16,20]. Most PTs treated themselves or sought treatment from a colleague [20]. As a consequence of their injury, $18 \%$ changed their work settings and $12 \%$ reduced patient contact time [10]. Pain and discomfort caused by WMSDs might have a significant impact on PTs' work and private life. Changing practice habits or work settings or even leaving the profession as a result of WMSDs have been also reported [38]. Physical therapists experience WMSDs of sufficient severity that one in 6 changes careers [15].

Physical therapists who worked in hospital-based settings had a greater prevalence of work-related LBP than non-hospital-based therapists $[11,12,18,20]$. This finding is consistent with Molumphy et al.'s study [10] of a high incidence of LBP among PTs in acute care settings. The greater prevalence of LBP among hospitalbased PTs may be attributed to the level of physical dependence of the patients. Patients in hospital settings are more likely to have acute and more extensive injuries than patients in ambulatory settings. Physical therapists are more likely to perform patient lifts and transfers, which involve greater physical effort in the hospital environment.

Rehabilitation centers appear to be the most dangerous work setting with the highest prevalence of work-related LBP due to a stressful and physically demanding work environment [8,17,24]. Waters and Rockefeller [39] have differentiated between patient handling tasks classified as "traditional" and those classified as "therapeutic" in a rehabilitation setting. Therapeutic tasks are designed to improve a patient's physical function and independence, whereas traditional tasks are designed to only offer a patient the needed help. Therefore, therapeutic tasks constitute a greater risk of musculoskeletal pain to the therapist since they require staying in an awkward position for long periods of time, thus, causing higher cumulative mechanical loads on the spine. This could also explain the highest prevalence of work-related LBP in PTs working in rehabilitation.

The LBP literature among hospital workers and health professionals has focused on LBP among the nursing staff. A higher range reported in Turkish studies, demonstrated that approximately $65-88 \%$ of nurses experience LBP [40-42]. These results suggest that nurses have the highest prevalence of LBP of all hospital workers. However, Alperovitch-Najenson et al. [22] have found a very high (73.1\%) 12-month prevalence of LBP among PTs, significantly higher than the one reported by the nurses (43.9\%), in the same rehabilitation hospital.

Responses to work-related LBP must include adopting one or more self-protective behaviors or using various aids and equipment. In addition, PTs may seek treatment, modify ADL and leisure (lifestyle) or make changes in their specialty area, either within the profession or by leaving it altogether as a consequence of work related LBP. Physical therapists experience WMSDs of sufficient severity that 1 in 6 changes careers [15].

Interestingly, PTs do not use lifts for a transfer of a patient and sliding sheets for repositioning a patient in the bed. Moreover, if their knowledge and clinical experience in 
musculoskeletal disorders/injuries do not prevent their own WMSDs, adopting new work techniques should be required, especially when using mechanical aids while working with patients. Physical therapists, despite their knowledge as to body mechanics and injury prevention, are no exception [20,24].

\section{CONCLUSIONS}

The practice of physical therapy and its specialized nature create musculoskeletal problems for PTs. The extent of musculoskeletal disorders among PTs suggests that their skills and knowledge are not effective in preventing WMSDs. We believe that specific strategies should be developed to reduce work-related LBP thus, preventing potentially disabling conditions. Majority of the studies have not concentrated on the use of aids and equipment such as lifts and sliding sheets. Therefore, further investigation is needed to estimate the influence of using different lifts and mechanical aids while treating patients, and thereby reducing WMSDs, and specifically LBP amongst PTs.

\section{ACKNOWLEDGMENTS}

The authors thank Mrs. Phyllis Curchack Kornspan for her English editorial services.

\section{REFERENCES}

1. Bernard BP, editor. Musculoskeletal disorders and workplace factors. A critical review of epidemiologic evidence for work-related musculoskeletal disorders of the neck, upper extremity, and low back. Washington (DC): US Department of Health and Human Services, National Institute of Occupational Safety and Health; 1997.

2. World Health Organization. Identification and control of work-related diseases. Geneva: The Organization; 1985. Technical Report Series No. 714.

3. Sharan D, Ajeesh PS. Injury prevention in physiotherapists A scientific review. Work. 2012;41 Suppl 1:1855-9, http:// dx.doi.org/10.3233/WOR-2012-0397-1855.
4. Bureau of Labor Statistics [Internet]. Washington (DC): The Bureau; 2009 [cited 2013 Mar 5]. Workplace injury and illness - 2009. Available from: http://www.bls.gov/news.release/archives/osh_10212010.pdf.

5. Hanson H, Wagner M, Monopoli V, Keysor J. Low back pain in physical therapists: A cultural approach to analysis and intervention. Work. 2007;28(2):145-51.

6. Campo MA, Weiser S, Koenig KL, Nordin M. Workrelated musculoskeletal disorders in physical therapists: A prospective cohort study with 1-year follow-up. Phys Ther. 2008;88(5):608-19, http://dx.doi.org/10.2522/ptj. 20070127.

7. Glover W, McGregor A, Sullivan C, Hague J. Work-related musculoskeletal disorders affecting members of the Chartered Society of Physiotherapy. Physiotherapy. 2005;91: 138-47, http://dx.doi.org/10.1016/j.physio.2005.06.001.

8. Holder N, Clark H, DiBlasio J, Hughes C, Scherpf J, Harding L, et al. Cause, prevalence and response to occupational musculoskeletal injuries reported by physical therapists and physical therapists assistants. Phys Ther. 1999;79:642-52.

9. Mierzejewski M, Kumaar S. Prevalence of low back pain among physical therapists in Edmonton, Canada. Disabil Rehabil. 1997;19(8):309-17, http://dx.doi.org/10.3109/ 09638289709166544.

10. Molumphy M, Unger B, Jensen GM, Lopopolo RB. Incidence of work-related low back pain in physical therapists. Phys Ther. 1985;65(4):482-6.

11. Salik Y, Ozcan A. Work-related musculoskeletal disorders: A survey of physical therapists in Izmir-Turkey. BMC Musculoskelet Disord. 2004;5:27, http://dx.doi.org/10.1186/14712474-5-27.

12. Shehab D, Al-Jarallah K, Moussa M, Adham N. Prevalence of low back pain among physical therapists in $\mathrm{Ku}$ wait. Med Princ Pract. 2003;12(4):224-30, http://dx.doi. org/10.1159/000072288.

13. King P, Huddleston W, Darragh AR. Work-related musculoskeletal disorders and injuries: Differences among older and 
younger occupational and physical therapists. J Occup Rehabil. 2009;19(3):274-83, http://dx.doi.org/10.1007/s10926-009-9184-1.

14. Punnett L, Wegman DH. Work-related musculoskeletal disorders: The epidemiologic evidence and the debate. J Electromyogr Kinesiol. 2004;14(1):13-23, http://dx.doi. org/10.1016/j.jelekin.2003.09.015.

15. Cromie JE, Robertson VJ, Best MO. Work-related musculoskeletal disorders in physical therapists: Prevalence, severity, risks, and responses. Phys Ther. 2000;80(4):336-51.

16. West DJ, Gardner D. Occupational injuries of physiotherapists in North and Central Queensland. Aust J Physiother. 2001;47(3):179-86, http://dx.doi.org/10.1016/S0004 -9514(14)60265-8.

17. Rozenfeld V, Ribak J, Danziger J, Tsamir J, Carmeli E. Prevalence, risk factors and preventive strategies in work-related musculoskeletal disorders among Israeli physical therapists. Physiother Res Int. 2010;15(3):176-84, http://dx.doi. org/10.1002/pri.440.

18. Alrowayeh HN, Alshatti TA, Aljadi SH, Fares M, Alshamire MM, Alwazan SS. Prevalence, characteristics, and impacts of work-related musculoskeletal disorders: A survey among physical therapists in the State of Kuwait. BMC Musculoskelet Disord. 2010;11:116, http://dx.doi. org/10.1186/1471-2474-11-116.

19. Rugelj D. Low back pain and other work-related musculoskeletal problems among physiotherapists. Appl Ergon. 2003;34(6):635-9, http://dx.doi.org/10.1016/S0003-6870(03) 00059-0.

20. Bork BE, Cook TM, Rosecrance JC, Engelhardt KA, Thomason MJ, Wauford IJ, et al. Work-related musculoskeletal disorders among physical therapists. Phys Ther. 1996;76(8):827-35.

21. Adegoke BO, Akodu AK, Oyeyemi AL. Work-related musculoskeletal disorders among Nigerian physiotherapists. BMC Musculoskelet Disord. 2008;9:112, http://dx.doi. org/10.1186/1471-2474-9-112.

22. Alperovitch-NajensonD, TregerI,KalichmanL.Physicaltherapists versus nurses in a rehabilitation hospital: Comparing prevalence of work-related musculoskeletal complaints and working conditions. Arch Environ Occup Health. 2014; 69(1):33-9, http://dx.doi.org/10.1080/19338244.2012.719555.

23. Waters T, Collins J, Galinsky T, Caruso C. NIOSH research efforts to prevent musculoskeletal disorders in the healthcare industry. Orthop Nurs. 2006;25(6):380-9, http://dx.doi. org/10.1097/00006416-200611000-00007.

24. Scholey M, Hair M. Back pain in physiotherapists involved in back care education. Ergonomics. 1989;32(2):179-90, http://dx.doi.org/10.1080/00140138908966078.

25. Landry MD, Raman SR, Sulway C, Golightly YM, Hamdan E. Prevalence and risk factors associated with low back pain among health care providers in a Kuwait hospital. Spine. 2008;33(5):539-45, http://dx.doi.org/10.1097/ BRS.0b013e3181657df7.

26. Pransky GS, Benjamin KL, Savageau JA, Currivan D, Fletcher K. Outcomes in work-related injuries: A comparison of older and younger workers. Am J Ind Med. 2005;47(2): 104-12, http://dx.doi.org/10.1002/ajim.20122.

27. Benjamin K, Pransky G. Occupational injuries and the older worker: Challenges in research, policy, and practice. Southwest J Aging. 2001;16:47-61.

28. Garg A. Ergonomics and the older worker: An overview. Exp Aging Res. 1991;17(3):143-55.

29. D’Arcy LP, Sasai Y, Stearns SC. Do assistive devices, training, and workload affect injury incidence? Prevention efforts by nursing homes and back injuries among nursing assistants. J Adv Nurs. 2012;68(4):836-45, http://dx.doi. org/10.1111/j.1365-2648.2011.05785.x.

30. Robertson LD, Changsut R, Ramos LS, Jones DW. Influence of job and personal risk factors on safety limits for kinesiotherapists performing a stressful clinical lifting task. Clin Kinesiol. 1993;47(1):7-16.

31. Holmström EB, Lindell J, Moritz U. Low back and neck/ shoulder pain in construction workers: Occupational workload and psychosocial risk factors. Part 1: Relationship to low back pain. Spine. 1992;17(6):663-71, http://dx.doi. org/10.1097/00007632-199206000-00005. 
32. Vuori I. Exercise and physical health: Musculoskeletal health and functional capabilities. Res Q Exerc Sport. 1995;66(4): 276-85, http://dx.doi.org/10.1080/02701367.1995.10607912.

33. Sutton GS, Bartel MR. Soft-tissue mobilization techniques for the hand therapist. J Hand Ther. 1994;7(3):185-92, http://dx.doi.org/10.1016/S0894-1130(12)80060-3.

34. Cromie JE, Robertson VJ, Best MO. Occupational health and safety in physiotherapy: Guidelines for practice. Aust J Physiother. 2001;47(1):43-51, http://dx.doi.org/10.1016/ S0004-9514(14)60297-X.

35. Manual handling regulations. Melbourne: Information Victoria, State Government Bookshop; 1999.

36. Darragh AR, Huddleston W, King P. Work-related musculoskeletal injuries and disorders among occupational and physical therapists. Am J Occup Ther. 2009;63(3):351-62, http://dx.doi.org/10.5014/ajot.63.3.351.

37. Breslin FC, Smith P. Age-related differences in work injuries: A multivariate, population-based study. Am J Ind Med. 2005;48(1):50-6, http://dx.doi.org/10.1002/ajim.20185.
38. Cromie JE, Robertson VJ, Best MO. Work-related musculoskeletal disorders and the culture of physical therapy. Phys Ther. 2002;82(5):459-72.

39. Waters TR, Rockefeller K. Safe patient handling for rehabilitation professionals. Rehabil Nurs. 2010;35(5):216-22, http://dx.doi.org/10.1002/j.2048-7940.2010.tb00050.x.

40. Karahan A, Bayraktar N. Determination of the usage of body mechanics in clinical settings and the occurrence of low back pain in nurses. Int J Nurs Stud. 2004;41(1):67-75, http://dx.doi.org/10.1016/S0020-7489(03)00083-X.

41. Tezel A. Musculoskeletal complaints among a group of Turkish nurses. Int J Neurosci. 2005;115(6):871-80, http://dx.doi. org/10.1080/00207450590897941.

42. Karahan A, Kav S, Abbasoglu A, Dogan N. Low back pain: Prevalence and associated risk factors among hospital staff. J Adv Nurs. 2009;65(3):516-24, http://dx.doi.org/10.1111/ j.1365-2648.2008.04905.x.

This work is available in Open Access model and licensed under a Creative Commons Attribution-NonCommercial 3.0 Poland License - http://creativecommons.org/ licenses/by-nc/3.0/pl/deed.en. 